\title{
PENGARUH KOMUNIKASI ORGANISASI (ORGANIZATIONAL COMMUNICATION) DAN KEADILAN DISTRIBUTIF (DISTRIBUTIVE JUSTICE) TERHADAP KINERJA GURU HONORER SMA NEGERI DI KABUPATEN BEKASI
}

\author{
Endah Susilowati*
}

\begin{abstract}
The objective of research is to obtain information about the effect of organizational communication and distributive justice on job performance on honorer teachers. It was a quantitative research with survey method in senior high school in Bekasi. The research was conducted to all of state senior high school teachers at Bekasi regency by using a survey method with path analysis applied in testing hypothesis. The number 86 teacers as sample was selected by using Slovin formula. The research conclude: (1) there is direct effect of organizational communication on job performance. (2) there is direct effect of distributive justice on job performance, and (3) there is direct effect of organizational communication on distributive justice. Therefore to enhance teacher's job performance can be carried out by organizational communication and distributive justice.
\end{abstract}

Keywords: Organizational communication, dsitributive justice, job performance

\section{PENDAHULUAN}

Pendidikan merupakan bagian penting dalam keberlangsungan kemajuan sebuah bangsa dan peradaban. Bahkan salah satu faktor penting dalam Indeks Pembangunan Manusia (IPM) atau sering dikenal Human Development Index menurut Perserikatan Bangsa-Bangsa (PBB) adalah pendidikan, dua faktor berikutnya adalah angka harapan hidup dan kemampuan daya beli. Amanat Undang-undang di negeri ini sebenarnya menempatkan pendidikan adalah sesuatu yang krusial. Undang-Undang Dasar 1945 (Amandemen Bab XIII Pasal 31 ayat 1 tegas menyatakan bahwa, "setiap warga negara berhak mendapatkan pendidikan". Tidak peduli bagaimana status kaya atau miskin.

Pendidikan bukan hanya sekenar mentransfer ilmu (transfer of knowledge) melainkan juga transfer nilai (transfer of value) sehingga menjadi bangsa yang beradab dan bermartabat di mata dunia. Sebagaimana amanah UU Sisdiknas No. 20 tahun 2003 bahwa, "pendidikan bertujuan untuk berkembangnya potensi peserta didik agar menjadi manusia yang beriman dan bertakwa kepada Tuhan Yang Maha Esa, berakhlak mulia, sehat, berilmu, cakap, kreatif, mandiri, dan menjadi warga negara yang demokratis serta bertanggung jawab". Hal yang sangat ironi adalah IPM Indonesia seperti dirilis oleh United Nation Development Program (UNDP) menempatkan Indonesia pada posisi ke-121 dari 187 negara sejajar dengan IPM Afrika Selatan.

\footnotetext{
* Staf Pengajar di STAI Sabili Cikarang Kabupaten bekasi
} 
Ujung tombak pendidikan di Indonesia adalah guru, seorang pahlawan tanpa tanda jasa ibarat penerang dalam gulita. Indonesia kini masih menyisakan permasalahan kesejahteraan guru terutama guru honorer. Hal ini pernah diangkat dalam headline warta kompas yang menyatakan, "nasib guru honorer semakin suram". Kesejahteraan yang minim membuat kinerja guru honorer tidak bisa optimal. Hal inilah yang melatarbelakangi beberapa oknum guru honorer yang seharusnya menjadi tauladan justru menghalalkan segala cara untuk menjadi PNS sebagaimana dirilis oleh portal resmi lowongan kerja CPNS Indonesia (LKCI) 2012-2013, "Dokumen Palsu, Ribuan Honorer K1 Gagal dapat Nomor Induk Pegawai (NIP)".

Hal serupa juga terjadi di Bekasi, sebanyak 43 calon pegawai negeri sipil ( $\underline{\mathrm{CPNS}})$ kategori 2 di Bekasi kedapatan memalsukan data. Badan Kepegawaian Daerah (BKD) Kota Bekasi menemukannya setelah uji publik terhadap CPNS. Kabid Pembinaan Kepegawaian (BKD) dalam tulisan yang sama juga menambahkan bahwa modus yang dilakukan adalah mengubah tahun masa kerja di bawah 2005. Hal ini diperparah ketika dirasakannya ada sebuah ketidakadilan dalam berbagai hal seperti gaji yang sangat berbeda drastis, pengakuan, tugas-tugas kerja dan yang lainnya. Hal ini ditunjukkan dengan intensitas yang cukup sering guru honorer yang berunjuk rasa. Dalam portal resmi kemendikbud, mengungkapkan "'mendikbud terima guru bantu yang berunjuk rasa". Seseorang akan merasa nyaman ketika output yang dikeluarkan seimbang dengan input yang didapatkan. Terdapat dua tipe keadilan yang menjadi fokus penting para anggota, yaitu keadilan distributif dan keadilan prosedural. Keadilan distributif berkaitan erat dengan distribusi hasil, sedangkan keadilan prosedural lebih keada pelaksanaan prosedur dalam organisasi.

Dalam penelitian ini akan memfokuskan bagaimana pengaruh keadilan distributif terhadap kinerja. Guru dalam sebuah organisasi sekolah dimungkinkan akan memiliki kinerja yang baik apabila mendapat perlakuan adil dalam organisasi di sekolahnya. Faktor lain selain rasa ketidakadilan yang dirasakan, komunikasi yang kurang sehat dapat memperparah kondisi yang ada. Manusia adalah makhluk sosial yang menuntut dirinya untuk membutuhkan dan berinteraksi dengan orang lain. Sebuah pekerjaan atau tugas akan terasa lebih ringan dan lebih cepat terselesaikan apabila dikerjakan bersama dibandingkan kita hanya bekerja seorang diri.

Hal inilah yang melatarbelakangi kebutuhan akan berorganisasi dan berinteraksi satu sama lain. Memahami pengertian organisasi penting karena dapat membantu kita untuk membentuk suatu tim kerja atau pembagian tugas untuk aktifitas tertentu. Interaksi dan kerja sama antara seseorang ini akan terus berkembang dengan teratur sehingga membentuk wadah yang kemudian sering disebut dengan organisasi. Organisasi merupakan unit terkoordinasi yang terdiri dari setidaknya dua orang yang berfungsi untuk mencapai tujuan bersama atau sekumpulan sasaran. Organisasi akhirnya menjadi kebutuhan dalam kehidupan sosial. Seperti halnya sekolah juga merupakan unit organisasi yang didalamnya terdapat pembagian tugas yang jelas. Untuk mencapai tujuan sebuah organisasi tentunya membutuhkan sebuah proses, salah satunya adalah komunikasi.

Semua makhluk hidup pada dasarnya tidak lepas dari komunikasi. Demikian juga dengan sebuah organisasi sekolah. Dalam setiap organisasi yang diisi oleh sumber daya manusia (SDM), ada yang berperan sebagai pemimpin, dan sebagian besar lainnya berperan sebagai anggota. Semua orang yang terlibat dalam organisasi tersebut akan melakukan komunikasi. Tidak ada organisasi tanpa komunikasi, karena komunikasi merupakan bagian yang tak terpisahkan dalam proses interaksi sosial. Untuk memaksimalkan kinerja baik individu maupun kelompok dalam organisasi dituntut 
untuk mampu membangun komunikasi yang baik. Dalam kehidupan berorganisasi tidak mungkin lepas dari berkomunikasi. Komunikasi bukan hanya sekedar transfer makna melainkan makna itu pun harus bisa dimengerti. Komunikasi diibaratkan seperti darah yang mengaliri seluruh badan untuk beraktivitas, sehingga menepati posisi penting. Komunikasi memiliki fungsi yang sangat penting dalam laju sebuah organisasi. Ketika komunikasi efektif, itu akan cenderung mendorong kinerja dan kepuasan kerja yang lebih baik.

Dapat dibayangkan ketika proses alur komunikasi tersumbat dalam sebuah organisasi, maka bisa dipastikan akan berimbas dengan kinerja organisasi tersebut. Terdapat banyak faktor yang dapat mempengaruhi kinerja seorang guru dalam sebuah organisasi sekolah, namun dalam penelitian ini akan lebih menfokuskan pada apakah komunikasi organisasi dan keadilan distributif berkontribusi dalam memberikan pengaruh terhadap kinerja guru honorer SMA Negeri dalam melaksanakan tugas pokok dan fungsinya sebagai guru yang sudah diatur dalam Undang-undang guru dan dosen No. 14 tahun 2005. Berdasarkan permasalahan yang ada peneliti tertarik meneiti mengenai pengaruh komunikasi organisasi dan keadilan distributif terhadap kinerja guru honorer SMA Negeri di Kabupaten Bekasi.

\section{Kinerja (Job Performance)}

Gibson et al (2009:372) mendefinisikan "job performance is the outcomes of jobs that relate to the purposes of the organization such as quality, efficiency, and other criteria of effectiveness". Definisi ini mengandung makna bahwa kinerja merupakan hasil pekerjaan yang berhubungan dengan tujuan dari organisasi seperti kualitas, efisiensi, dan kriteria lain demi efektivitas organisasi. Pendapat ini lebih menekankan bahwa kinerja sangat erat kaitannya dengan tujuan sebuah organisasi. Pendapat senada disampaikan oleh Schermerhorn (2005:386) mengemukakan, "job performance is measured as the quantity and quality of task accomplished by an individual or group". Kinerja diukur sebagai kuantitas dan kualitas tugas yang dicapai oleh individu atau kelompok. Schermerhorn lebih berfokus pada capaian tugas baik secara kualitas mutu maupun kuantitas atau dari segi jumlah yang dicapai.

Jex (2008:114) mendefinisikan "job performance is a deceptively simple term. At the most general level, it can be defined simply as "all of the behaviors employees engage in while at work". Kinerja didefinisikan secara sederhana di tingkat paling umum merupakan keseluruhan perilaku karyawan yang terlibat dalam pekerjaan dalam sementara waktu di tempat kerja. Sedangkan Colquitt, LePine dan Wesson (2011:35) mendefinisikan bahwa, "job performance is formally defined as the value of the set of employee behaviors that contribute, either positevely or negatively to organizational goal accomplishment". Kinerja yang dimaksud adalah secara formal didefinisikan sebagai nilai dari serangkaian perilaku karyawan yang memberikan kontribusi, baik positif maupun negatif terhadap pencapaian tujuan organisasi.

Pendapat berbeda dikemukakan oleh Williams (2009: 473), "job performance is how well some one performs the requirements of the job". Kinerja merupakan seberapa baik seseorang melakukan pekerjaan sesuai dengan ketentuan yang ada. Hal ini mengindikasikan bahwa seseorang harus mengikuti standar operasional yang sudah ditetapkan oleh organisasi bukan mengikuti kehendak pribadi masing-masing.

Dari beberapa deskripsi konsep di atas, maka dapat disintesiskan kinerja adalah hasil dari serangkaian perilaku pekerjaan individu atau kelompok yang memberi 
kontribusi terhadap organisasi. Kinerja dapat diukur dengan indikator meliputi; kualitas kerja, kuantitas kerja, kehadiran di tempat kerja, mudah beradaptasi, inisiatif dan kerjasama.

\section{Komunikasi Organisasi (Organizational Communication)}

Eisenberg dan Goodall (2001:5) mendefinisikan, "organizational communication is a subfield of the broader academic discipline of communication, which addresses similar questions across a wide range of social setting, including families, school, politics and the media. Komunikasi organisasi adalah merupakan sub dari disiplin ilmu komunikasi yang lebih luas, yang membahas pertanyaan-pertanyaan serupa di berbagai pengaturan sosial, termasuk keluarga, sekolah, politik dan media.

Littlejhon (1996:19) medefinisikan, "organizational communication is communication that occurs in large cooperative network and includes virtually all aspect of both interpersonal and group communicationnand includes topics such as the structure and function of organization, human relations, communication and the process of organizing and organizational culture". Komunikasi organisasi adalah komunikasi yang terjadi di jaringan kerjasama yang cukup besar dan mencakup hampir semua aspek komunikasi interpersonal dan komunikasi kelompok termasuk topik seperti struktur dan fungsi dari organisasi, hubungan manusia, komunikasi dan proses pengorganisasian dan budaya organisasi.

Pendapat lain dikemukakan oleh Goldhaber (1986:

9) "organizational communication is the process of creating, and exchanging messages within a network of interdependent relationship to cope with environmental uncertainly". Proses menciptakan, dan bertukar pesan dalam jaringan hubungan saling bergantung untuk mengatasi ketidakpastian lingkungan oleh individu atau kelompok.

Pendapat yang cukup singkat dikemukakan oleh Devito (2009:5) mendefinisikan komunikasi organisasi sebagai, "organizational communication is communication that takes place within an organization among members of organization". Menurut Devito, komunikasi organisasi adalah komunikasi yang terjadi dalam sebuah organisasi di antara anggota organisasi. Pendapat ini cukup jelas bahwa komunikasi yang terjadi dalam lingkup organisasi disebut dengan komunikasi organisasi.

Melengkapi konsep di atas Daniels, Spiker dan Papa (1997:4) mendefinisikan, "organizational communication is concerned primarily with the content and structure of human interaction in organization's day-to-day activities". Komunikasi organisasi adalah komunikasi yang memberi perhatian utama terhadap isi dan struktur dari interaksi manusia dalam organisasi dalam aktivitasnya sehari-hari. Ada banyak faktor yang mempengaruhi sebuah komunikasi organisasi sebagaimana diungkap Daniels, Spiker dan Papa, "many studies of organizational communication factors have shown that conditions suchs as participation, opennes, supportiveness, and information adequacy are related not only to member's satisfaction but also to member commitment to the the organization. Banyak studi mengenai faktor-faktor komunikasi organisasi seperti partisipasi, keterbukaan, daya dukung informasi dan ketercukupan informasi sangat berhubungan dengan kepuasan dan komitmen seseorang dalam berorganisasi.

Dari beberapa deskripsi konsep di atas, maka dapat disintesiskan bahwa komunikasi organisasi adalah proses penyampaian dan saling bertukar pesan baik secara formal maupun informal antara dua orang atau lebih dalam sebuah jaringan organisasi. Komunikasi organisasi dapat diukur dengan menggunakan indikator 
partisipasi, keterbukaan informasi, daya dukung informasi, ketercukupan informasi, alur komunikasi, dan hambatan komunikasi.

\section{Keadilan Distributif (Distributive Justice)}

Robbins dan Judge (2011: 258) mendefinisikan keadilan distributif, "the employee's perceived fairness of the amount and allocation of rewards among individuals". Keadilan distributif adalah keadilan yang dirasakan oleh pekerja mengenai jumlah dan alokasi hadiah (rewards) antar individu. Pendapat senada dikemukakan oleh Greenberg (2010:37), "distributive justice is the form of organizational justice that focuses on people's beliefs that they have received fair amounts of valued work related outcomes (e.g., pay, recognition, etc)". Menurut Greenberg, Keadilan distributif adalah bentuk dari keadilan organisasi yang berfokus pada keyakinan orang bahwa mereka telah menerima secara adil jumlah pengharagaan yang terkait dengan hasil bekerja (misalnya, upah, pengakuan, dll). Scermerhorn (2005:92) mendefinisikan, "distributive justice is concerned that people are treated the same regardless of personal characteristic". Keadilan distributif mengacu pada bahwa orang-orang diperlakukan sama terlepas dari karakteristik pribadinya masing-masing yang berbeda. Sedangkan menurutr Hughes, Ginnett dan Curphy (2009:421) mendefinisikan, "distributive justice is concerns followers perceptions of whether the level of reward or punishment is commensurate with an individual's performance or infraction". Keadilan distributif memberi perhatian pada masalah persepsi apakah tingkat hadiah atau hukuman sepadan dengan kinerja atau pelanggaran yang dilakukan oleh individu. Ivancevich, Matteson dan konopaske (2006:125) juga menuliskan mengenai keadilan distributif bahwa, "distributive justice is the perceived fairness of how resources and rewards are distributed throughout an organization". Keadilan distributif adalah keadilan yang dirasakan dari bagaimana sumber daya dan hadiah atau upah didistribusikan ke seluruh organisasi.

Pendapat yang cukup lengkap yang mengungkap Keadilan distributif meliputi apa saja dikemukakan oleh Colquitt, Lepine dan Wesson (2011:226), "distributive justice reflects the perceived fairness of decision making outcomes, such as pay, rewards, evaluations, promotions, and work assignments are allocated using proper norms. Keadilan distributif mencerminkan keadilan yang dirasakan dari hasil pengambilan keputusan, seperti upah, hadiah, evaluasi, promosi, dan tugas-tugas kerja dialokasikan secara tepat sesuai dengan norma-norma yang ada. Pendapat ini cenderung berpendapat bahwa keadilan distributif berkaitan dengan hasil kinerja yang didistribusikan secara adil sesuai dengan ketentuan yang berlaku.

Dari beberapa deskripsi konsep di atas, maka dapat disintesiskan keadilan distributif adalah keadilan yang dirasakan oleh individu terkait dengan pendistribusian dan pengalokasian dari hasil pengambilan keputusan. Keadilan distributif dapat diukur dengan melihat keadilan pada pemberian upah, pemberian hadiah, evaluasi, promosi, pengakuan, pemberian sanksi dan pembagian tugas-tugas kerja. 


\section{METODE}

Penelitian ini dilaksanakan di kabupaten Bekasi yang meliputi 5 SMA Negeri yang ada di kabupaten Bekasi. Teknik pengambilan sampel yang digunakan adalah simple random sampling dengan jumlah 86 guru. Metode yang digunakan dalam penelitian ini adalah metode survey dengan menggunakan kuesioner sebagai alat pengumpul data pokok dan dokumentasi.

Penelitian ini menggunakan analisis jalur (path analysis) untuk mengetahui adanya pengaruh antar variabel sesuai dengan model kausal yang terbentuk. Sebelum kuesioner digunakan, terlebih dahulu dilakukan ujicoba untuk menentukan validitas dan reliabilitas instrumen. Hasil tersebut digunakan sebagi instrumen untuk mengambil data di lapangan. Adapun analisi data meliputi: 1) deskripsi data 2) uji prasyarat analisis normalitas dan 3) analisis jalur yang meliputi analisis model, pengujian hipotesis dan penentuan tingkat pengaruh.

\section{HASIL DAN PEMBAHASAN}

\section{Pengaruh langsung Komunikasi Organisasi (Organizational Communication) terhadap Kinerja}

Dari hasil perhitungan analisis jalur pengaruh langsung komunikasi organisasi terhadap kinerja guru honorer SMA Negeri di Kabupaten bekasi diperoleh nilai koefisien jalur $p_{31}=0,350$ dan nilai koefisien korelasi $r_{13}=0,444$. Hasil penelitian ini sesuai dengan Lily Wahyuni (2010) mahasisiwi pasca sarjana Universitas Diponegoro yang dimuat di Jurnal mengungkapkan dalam abstraknya, " research findings showed that organization communication significant influence the performance". Penelitian tersebut menunjukkan bahwa komunikasi organisasi memberikan pengaruh yang signifikan terhadap kinerja guru honorer SMA Negeri di Kabupaten Bekasi. Komunikasi organisasi yang dilakukan secara tepat mengakibatkan peningkatan kinerja guru honorer SMA Negeri di Kabupaten Bekasi.

Pengaruh langsung Keadilan Distributif (Distributive Justice) terhadap Kinerja Dari hasil perhitungan analisis jalur pengaruh langsung keadilan distributif terhadap kinerja guru honorer SMA Negeri di Kabupaten bekasi diperoleh nilai koefisien jalur $p_{32}=0,333$ dan nilai koefisien korelasi $r_{23}=0,432$. Hasil penelitian ini sesuai dengan penelitian Taylor dan Francis(1999) yang mengungkapkan dalam abstractnya yang dimuat dalam The Journal of Psychology: Interdisciplinary and Applied Volume 133 Issue 2 tahun 1999 bahwa, “...providing interactional and distributive justice by explaining why specific consequences were received did improve their subsequent task performance". Baik keadilan interaksional maupun keadilan distributif keduanya memberikan konsekuensi dalam meningkatkan kinerja tugas. Dengan demikian ketepatan dalam keadilan distributif mengakibatkan peningkatan kinerja tugas guru honorer SMA Negeri di Kabupaten Bekasi.

Pengaruh langsung Komunikasi Organisasi (Organizational Communication) terhadap Keadilan Distributif (Distributive Justice) 
Dari hasil perhitungan analisis jalur pengaruh langsung komunikasi organisasi terhadap keadilan distributif guru honorer SMA Negeri di Kabupaten bekasi diperoleh nilai koefisien jalur $p_{21}=0,283$ dan nilai koefisien korelasi $r_{12}=0,283$. Hasil penelitian ini 
sesuai dengan teori yang dikemukakan Collquitt dalam bukunya Organizational Behaviour: Improving Performance and Commitment in the Workplace. Dengan demikian komunikasi organisasi yang dilakukan secara tepat, mengakibatkan peningkatan guru honorer di SMA Negeri di Kabupaten Bekasi.

\section{PENUTUP}

\section{Kesimpulan.}

Dari hasil analisis data dan pembahasan tersebut di atas, maka dapat disimpulkankan hal-hal sebagai berikut:

1. Terdapat pengaruh langsung komunikasi organisasi terhadap kinerja. Artinya jika komunikasi organisasi di sekolah berjalan dengan baik dan lancar, maka akan dapat meningkatkan kinerja guru honorer di sekolah.

2. Terdapat pengaruh langsung keadilan distributif terhadap kinerja. Artinya jika keadilan distributif di sekolah dalam pengambilan keputusan dan distribusi hasil dirasakan adil, maka akan dapat meningkatkan kinerja guru honorer di sekolah.

3. Terdapat pengaruh langsung komunikasi organisasi terhadap keadilan distributif. Artinya komunikasi organisasi di sekolah yang baik akan dapat mendukung ketercapaian penerapan keadilan distributif dalam pengambilan keputusan dan pengalokasian distribusi hasil bagi guru honorer di sekolah.

Saran. Beberapa saran dapat diajukan peneliti untuk meningkatkan kinerja para guru honorer yaitu:

1. Kepala Dinas pendidikan kabupaten Bekasi dapat memberi perhatian lebih kepada nasib guru honorer di kabupaten bekasi.

2. Kepala sekolah sebagai leader dan juga klimator berupaya menciptakan iklim komunikasi organisasi yang baik serta memperhatikan sisi-sisi keadilan distributif bagi guru honorer di sekolahnya.

3. Para guru PNS sebagai rekan sejawat agar menjalin komunikasi organisasi yang baik dengan para guru honorer sehingga perbedaan status tidak menjadikan permasalahan dalam bersosialisasi dan berkomunikasi.

4. Lembaga/pihak sekolah hendaknya mampu mewujudkan keadilan distributif yang diharapkan dan menciptakan iklim komunikasi yang kondusif sehingga para guru honorer merasa nyaman bekerja dan merasa menjadi bagian dari organisasinya/ sekolah tempat mereka bekerja.

5. Para guru honorer agar terus menunjukkan kinerja yang lebih baik dalam pengajaran dan interaksi dengan warga sekolah dan berupaya mengukir prestasi. 


\section{DAFTAR RUJUKAN}

Colquitt, Jason A, Jeffery Lepine dan Michael J. Wesson, Organizational Behaviour: Improving Performance and Commitment in the Workplace (New york: Mcgraw-Hill Companies, 2011)

Daniels D. Tom, Barry K. Spiker dan Michael J. Papa, Perspective on Organizatiponal Communication (New York: McGrawHill, 1997)

Devito, Joseph A. Communication: The Basic Course (New York: Pearson Education,Inc, 2009)

Eisenberg, Eric M dan dan H.L. Goodall. JR, Organizational Communication: Balancing Creativity and Constraint (Boston:Bedford/St.martin's, 2001)

Gibson et al, Organization: Behaviour, structure, processes (England: Pearson education limited,2012)

Goldhaber, Geral M. Organizational Communication (Iowa: Brown Publisher, 1986)

Greenberg, Jerald. Managing Behaviour in Organizaions (New Jersey: Pearson education, 2010)

Hughes, Richard. L, Robert C. Ginnett dan Gordon J Curphy, Leadership: Enhancing the Lesson of Experience (New York: McGraw-Hill International edition, 2009)

Ivancevich, Jhon M., Robert Konopaske, Michael T. Matteson, Organizational Behavior and Management (New York: McGraw-Hill, 2008)

Jex, Steve M., Thomas W. Britt. Organizational Psycology: A Scientist-Practitioner Approach (New York: John Wiley \& Sons, 2008)

Littlejohn, Stephen W. Theories of Human Communication (California: Wadsworth, Inc., 1996)

Luthans, Fred. Organizational Behaviour (New York: McGraw-Hill, 2011)

Robbins, Stephen P dan Timothy A. Judge, Organizational Behaviour (New Jersey:Prentice Hall, 2011)

Schermerhorn, Jhon R. Management, (USA: Jhon Wiley and Sons Inc, 2005)

Taylor dan Francis, "The Effects of Distributive and Procedural Justice on Performance", The Journal of Psychology: Interdisciplinary and Applied Vol. 133, Issue2, 1999. http:/ / www.tandfonline.com/doi/abs/10.1080/00223989909599732?journalCode= vjrl20 (diakses 1 april 2013)

Wahyuni, Lili. "Pengaruh Komunikasi Organisasi terhadap Kinerja Karyawan Bagian akuntansi dengan Komitmen Organisasi dan Tekanan Pekerjaan sebagai Variabel Intervening". (Diponegoro University. Masters Thesis, 2010). http://eprints.undip.ac.id/7843/ (diakses 4 april 2013)

Williams, Chuck. Management (USA: Jhon Wiley and Sons Inc, 2005) 
